\title{
O conto policial de Jorge Luis Borges: cânone e marginalidade
}

Andréa Lúcia Padrão Ângelo

Recebido 9, jan. 2007/ Aprovado 9, abr. 2007

\section{Resumo}

A obra de Jorge Luis Borges teve influência decisiva na definição do perfil do século XX, especialmente nas questões referentes ao mundo das letras. Escritor consagrado, demonstra inegável preferência pela literatura marginal, pelo texto fora das tradições canônicas. O presente trabalho enfoca dois contos de Borges em um gênero ainda considerado "menor", o policial. Mostra, também, como essas narrativas aparecem vinculadas a preocupações que ultrapassam o gênero, abrangendo elementos comuns ao universo borgiano: filosóficos, teológicos, místicos, míticos, metafísicos e históricos.

Palavras-chave: Borges; Cânone; Transgressão; Policial. 
Se observarmos o perfil do nosso tempo, é possível verificar que a obra de Jorge Luis Borges tem nele influência decisiva, principalmente no que diz respeito às questões de literatura. Dentre os escritores da América Latina é certamente um dos mais lidos, discutidos e traduzidos no mundo todo; sua obra vem marcar um novo lugar para a recepção da literatura que aqui se produz, inclusive para a nossa maneira de falar. Em conseqüência do diálogo que provocou com autores europeus ou americanos, levou as especificidades da cultura latino-americana a diversas partes do mundo. Apesar de escritor consagrado e de fazer chegar o nome da Argentina e da sua Buenos Aires às diversas línguas para as quais sua obra é traduzida, peculiarmente demonstra uma notória preferência pela literatura marginal.

Borges ultraísta afirma que "o marginal é o mais belo", já em 1921. Essa estranha preferência de Borges pela literatura marginal ${ }^{1}$ inicia na juventude não só nos seus próprios textos, mas também se acha presente na seleção de seus autores preferidos, como Stevenson, De Quincey, Chesterton. Para Balderston, a excêntrica avaliação de Borges de que, por exemplo, Robert Louis Stevenson é uma das figuras mais amoráveis da literatura inglesa constitui uma "traição" ao chamado corpo canônico da língua inglesa. E ao analisar a identificação de Borges com os citados autores, transformando-os em pontos centrais da tradição de língua inglesa, declara que o escritor argentino cria novos precursores, reescrevendo a tradição inglesa a partir de Buenos Aires, a partir de sua perspectiva de "mero sudamericano" (BALDERSTON, 1984, p. 11). Pensamento semelhante é compartilhado por Sarlo, ao afirmar que Borges delineia um dos paradigmas da literatura argentina, ao construí-la no cruzamento da cultura européia com a "inflexión rioplatense del castellano en el escenario de un país marginal" (SARLO, 2003, p. 47). Assim, é possível observar, em parte de sua obra, a convivência de temas universais com a tradição dos compadritos e dos orilleros, das milongas e dos duelos com punhais. As orillas, "espacio imaginario que se contrapone, como um espejo infiel a la ciudad moderna despojada de qualidades estéticas e metafísicas" (SARLO, 2003, p. 48), constituem a periferia que Borges explora com seus orilleros; constituem o lugar onde o campo e a cidade se encontram e se desmancham, se destroem. Borges, dessa forma,

$\overline{1 \text { O marginal pode ser }}$ entendido como o comentário sobre textos existentes, o texto excêntrico, fora das tradições consagradas (BALDERSTON, 1984, p. 11).

2 Na década de 20, o termo 'orillas' referiase a bairros afastados e pobres, limítrofes com a cidade (SARLO, 2003, p. 48). libera "las orillas" do estigma social que as identificava, e faz delas um espaço literário, definindo ali um território original que lhe permite não só dialogar em pé de igualdade com a literatura ocidental, mas também implantar sua própria diferença em relação ao resto da literatura argentina. Ao fazer da margem uma estética pode-se dizer que Borges reafirma a especificidade, a argentinidade de sua literatura. Assim, a estética de margens, de que fala a crítica argentina, refere-se àquele aspecto da literatura de Borges em que os limites se confundem: “[...] ciudad estética 
sin centro, construida totalmente sobre la matriz de un margen" (SARLO, 2003, p. 51). Apesar de serem margens, contêm um manancial, capaz de dar origem, de gerar. E é a partir dessas margens que Borges constrói sua literatura de fronteiras, uma poética que muitas vezes se alimenta da diferença, por exemplo, entre o heterogêneo, o "gênero menor" e a erudição universalista dos seus contos e ensaios; uma poética que se alimenta da mescla do marginal e do popular com o consagrado.

Um gênero considerado "menor" a que Borges se dedica durante grande parte de sua vida literária é a narrativa policial, que se faz presente na sua formação desde a infância e atravessa sua maturidade literária como centro contínuo de interesse. Esse interesse deve-se, em parte, à influência exercida sobre ele pela literatura de língua inglesa, berço da narrativa policial. Impregnada com o tempo mágico, com o tema do duplo, com o sonho, com o pesadelo ou com uma realidade que freqüentemente se apresenta misteriosa, fantástica ou irreal, é principalmente na Grã-Bretanha que se realiza uma aproximação do sobrenatural com o gênero policial. Tal fato ocorre principalmente na obra de Chesterton, mas também na de outros escritores como Stevenson, autor de numerosas narrativas fantásticas como The strange case of Dr. Jekyll and Mr. Hyde e New Arabian Nights, que nos revela uma Londres fantástica, antecipatória das atmosferas policiais típicas de Chesterton. O especial interesse que Borges sente pela narrativa policial não se limita aos clássicos do gênero, que leu avidamente (de Poe a Chesterton), mas estende-se a escritores que considera de menor densidade literária, como Conan Doyle e Agatha Christie. Sua Antologia do conto policial, compilada em colaboração com Adolfo Bioy Casares, e publicada em dois volumes, em 1943 e 1951, com diversas reedições, nos dá testemunho dessa variedade de interesse e leituras. ${ }^{3}$ Isabel Stratta (1999, p. 55) considera que o interesse demonstrado por Borges por esse gênero literário se deve, em grande parte, a uma necessidade de atacar "o que considerava as tendências caóticas do romance contemporâneo". Segundo a autora, esse foi um mecanismo freqüentemente utilizado pelo autor argentino: ressaltar os méritos de um escritor ou de um gênero para, por contraste, evidenciar as falhas de outros (ou, ao contrário, atacar um para ressaltar o outro). Assim, ao elogiar a disciplina construtiva do policial,

No segundo volume dessa antologia estão publicados doze contos de autores de língua inglesa: nove britânicos e três norte-americanos. Tal fato certamente confirma, no gênero, a superioridade atribuída por Borges à literatura anglo-saxônica. evidencia o que chama de época de desordem da literatura: "el relato policial no prescinde nunca de un principio, de una trama $\mathrm{y}$ de un desenlace. Interjecciones y opiniones, incoherencias y confidencias agotan la literatura de nuestro tiempo; el relato policial representa un orden y la obligación de inventar." (BORGES, 1999a, p. 250).

Os contatos mais explícitos do Borges-escritor com o gênero iniciam-se em meados dos anos 30, prolongando-se no começo dos anos 50 (RIVERA, 1995, p. 133). São marcados por alguns 
textos ficcionais e por uma grande quantidade de artigos, resenhas, ensaios e prólogos em que o escritor se dedica a comentar narrativas, narradores e o próprio gênero. Dessa infinidade de textos compostos por Borges de um modo oblíquo e descontínuo, "pero sumamente coherentes" (STRATTA, 1999, p. 55), é possível extrair, além de um código estético que norteia suas composições literárias, uma teoria borgiana do conto policial.

Dentre um conjunto de publicações sobre o gênero, destacase o ensaio "Los laberintos policiales y Chesterton" (1999, p. 126-9), surgido em 1935, em Sur, por ocasião do lançamento do quinto e último volume das aventuras do Padre Brown, de Chesterton. ${ }^{4}$ Nesse ensaio, que pode ser considerado um dos mais importantes estudos de Borges sobre o policial, ele descreve a forma ideal da narrativa policial, distingue o romance do conto policial e propõe seis requisitos para o gênero:

1) “Un límite discrecional de seis personajes". Assim, as personagens devem ser poucas.

2) "Declaración de todos los términos del problema". Como um jogo, deve-se oferecer ao leitor todos os elementos necessários à resolução do enigma.

3) "Avara economía en los medios". Ou seja, os enigmas devem ser simples.

4) “Primacía del cómo sobre el quién...". Deve prevalecer a originalidade do argumento; dessa forma, a trama importa mais que as personagens.

5) "El pudor de la muerte". Supressão dos detalhes violentos e desnecessários à trama.

6) “Necesidad y maravilla en la solución". A resolução do enigma deve surgir quase como uma epifania e maravilhar o leitor.

Balderston $^{5}$ enfatiza a ausência de algumas convenções do

Outros comentários sobre Chesterton foram feitos em 22 de julho de 1936, também em Sur, no ensaio "Modos de G.K. Chesterton". E, finalmente, nos Anales de Buenos Aires, n. 20-22, out./dez. 1947, ao publicar uma "Nota sobre Chesterton".

BALDERSTON, Daniel. El asesinato considerado como una de las bellas artes. In: $E l$ precursor velado: R.L. Stevenson en la obra de Borges. Tradução de Eduardo Paz Leston. Buenos Aires: Sudamericana, 1985. Disponível em: <http://www.hum. au.dk/romansk/borges/ bsol/db5.htm>. Acesso em: 05 mar. 2005. gênero no código proposto por Borges. Para o crítico norte-americano, esses princípios, que o escritor argentino estabelece para orientar a narrativa policial, não devem ser encarados como leis canônicas, mas como constantes que dão estrutura a um gênero instável e sujeito a contínuas inovações. O próprio Borges afirma, ao resenhar Excellent Intentions, de Richard Hull: "entiendo que el género policial, como todos los géneros, vive de la continua y delicada infracción de sus leyes" (BORGES, 1996, p. 359, v. IV). Também no prólogo do livro Elogio de la sombra, Borges confessa o que considera uma "astúcia" utilizada em seus relatos: "recordar que las normas anteriores no son obligaciones y que el tiempo se encargará de abolirlas" (BORGES, 1996, p. 353, v.II).

Dessa forma, fixando apenas os limites que não devem ser ultrapassados sob pena de perder em rigor e interesse, o escritor sente-se à vontade para inovar em seus próprios contos.

É importante ressaltar que, ao lado de autores como Chesterton, Stevenson e Ellery Queen, Poe é uma das mais constantes 
referências na construção da teoria do policial para Borges. De acordo com o autor de Ficciones, a narrativa policial é tributária desse escritor, à medida que ele cria um gênero fantástico da inteligência, fazendo com que a literatura seja considerada "una operación de la mente, no del espíritu". Assim, "hablar del relato policial es hablar de Edgar Allan Poe, que inventó el género", sendo a literatura moderna "inconcebible sin Poe" (BORGES, 1997, p. 83-7).

Numa conferência sobre o conto policial, proferida em 1978, na Universidade de Belgrano, Borges tem a oportunidade de afirmar que:

Poe no quería que el género policial fuera un género realista, quería que fuera un género intelectual, un género fantástico si ustedes quieren, pero un género fantástico de la inteligencia, no de la imaginación solamente, de ambas cosas desde luego, pero sobre todo de la inteligencia. (BORGES, 1997, p. 94)

Assim, Borges mostra-se abertamente favorável ao conto policial racional, na sua vertente inglesa, criada pelo americano Poe e seu detetive Dupin. ${ }^{6}$ Por outro lado, rejeita a vertente americana da chamada série "noire" de Dashiell Hammett e Raymond Chandler. Na conferência sobre o conto policial, já referida anteriormente, Borges constata que o gênero policial apresenta-se nos Estados Unidos de forma realista, enfocando violência, inclusive de natureza sexual. E destaca o desaparecimento da história policial clássica, com suas características intelectuais, excetuando apenas os autores ingleses que ainda escrevem romances de enredo sóbrio, sem excessivo derramamento de sangue (BORGES, 1997, p. 103-4).

Na sua produção ficcional Borges imprimiu nova dimensão ao conto policial contemporâneo, introduzindo nele questões filosóficas e metafísicas e temas recorrentes na estética borgiana. O início da cronologia policial de Borges data de 1936, com a publicação de "El acercamiento a Almotásim", surgido primeiro como ensaio, em Historia de la eternidad, e depois como conto, em Ficciones; consiste no esboço bibliográfico de um livro fictício, caracterizado pelo que o autor, ironicamente, chama de "la primera novela policial escrita por un nativo de Bombay City" (RIVERA, 1995, p.133). Aqui Borges emprega esse procedimento, tão freqüente em seus ensaios, o de simular que um livro já existe e fazer sobre ele um resumo ou comentário. Em 1941, no Prólogo a "El jardín de senderos que se bifurcan", Borges afirma:

6 De forma curiosa se pode observar que o conto policial de estilo clássico, ou europeu, admirado por Borges, paradoxalmente nasceu na América, com Poe.
Desvarío laborioso y empobrecedor el de componer vastos libros; el de explayar en quinientas páginas una idea cuya perfecta exposición oral cabe en pocos minutos. Mejor procedimiento es simular que esos libros ya existen y ofrecer un resumen, un comentario. (BORGES, 1996, p. 429) 
Para Alazraki, esse comportamento, embora atenda ao ideal de economia verbal que confere ao seu estilo solidez e transparência, constitui, também, um dos meios dos quais Borges se utiliza para misturar ou confundir os limites do real e do irreal (ALAZRAKI, 1983, p. 75).

Em “El acercamiento a Almotásim" Borges leva o leitor a pressupor a existência de um romance - "la primera novela policial escrita por un nativo de Bombay" - que é resumida e comentada. Ao final, o resumo ou o comentário acaba por impor-nos a realidade do livro imaginado. Trata da história de um estudante de direito de Bombaim, que dedica sua vida à busca do homem de quem procede a claridade que percebera num homem vil. Assim, inicia uma peregrinação que abrange a extensa geografia do Industão. Observa-se, também, que todos os homens dos quais se aproxima e interroga têm uma parcela de Almotásim, origem dessa claridade almejada, e que essa parcela é maior nas pessoas das quais mais se aproxima. No desfecho do conto, o estudante chega a uma galeria e a incrível voz de Almotásim convida-o a entrar. No final de sua nota sobre a narrativa, Borges adiciona uma outra nota, que contém o resumo, agora, de um poema: Mantiq al-Tayr (Colóquio dos pássaros) de Muhammad ibn Ibrahim, místico persa, mais conhecido como Attar. Diz o poema que no centro da China os pássaros encontram uma pluma do Simurg (que significa trinta pássaros), seu rei e resolvem buscá-lo. Depois de inúmeras aventuras, somente trinta pássaros conseguem chegar à montanha do Simurg. "Lo contemplan al fin: perciben que ellos son el Simurg y que el Simurg es cada uno de ellos y todos" (BORGES, 1996, p. 463). Para Alazraki, este poema, que existe e não é uma criação de Borges, explica o final do romance simulado: a identidade do perseguido e do perseguidor. O estudante de Bombaim é Almotásim e Almotásim é o estudante e todos os homens. Da mesma forma, o Simurg é Deus e todos os homens são o Simurg. Ao apresentar as aventuras de um romance policial segundo o modelo de uma alegoria que expressa a crença panteísta do Sufismo, Borges evidencia o valor estético das doutrinas religiosas; aqui, as possibilidades literárias do panteísmo. Assim, quando mistura um resumo do Mantiq al Tayr com um resumo de uma obra fictícia, Borges faz com que o fictício (o romance policial) se encha de realidade e o real (o poema) adquira vislumbres de irrealidade. Também a própria estrutura do conto expressa a idéia panteísta de que tudo é todos, observável na inclusão de uma nota dentro de outra nota, de um resumo dentro de outro e a redução de ambos a versões diferentes de uma mesma doutrina (ALAZRAKI, 1983, p. 77-8).

Outro conto do gênero policial, "La muerte y la brújula", é, certamente, um dos mais celebrados do escritor argentino. Foi publicado em Sur, em maio de 1942, e posteriormente incluído 
em Ficciones (1944), livro que recebeu o Prêmio Internacional de Literatura, em 1961. Ler "La muerte y la brújula" significa penetrar simultaneamente em muitos mundos borgianos: do relato policial, da erudição livresca, das conjeturas, dos paradoxos, da ironia, de uma metafísica notável, da refutação do racionalismo. Esse conto tem como tema central a briga de sangue entre o detetive racional Erik Lönnrot e o chefe de uma quadrilha, o gângster Red Scharlach el Dândi, numa Buenos Aires visionária que tão freqüentemente é palco dos textos de Borges. Inimigos mortais, como indica a cor vermelha que partilham nos nomes, Lönnrot e Red Scharlach são duplos óbvios. "La muerte y la brújula" gira em torno de uma série de crimes e inicia com um assassinato cometido no Hôtel du Nord, na noite de 3 de dezembro, no Norte da cidade. Encarregados de investigar o crime, um comissário de polícia e o detetive Erik Lönnrot chegam ao local na manhã do dia 4 e são informados de que a vítima é o rabino Marcel Yarmolinsky, representante de Podólsk no Terceiro Congresso Talmúdico. Junto a seu corpo, aberto a faca, uma frase inconclusa: "La primera letra del Nombre ha sido articulada" (BORGES, 1996, p. 500 v.I). Lönnrot, um detetive racional como Dupin de Poe, busca explicações rabínicas para o crime, baseando-se nos livros que o morto carrega consigo: uma monografia sobre o Tetragrámaton, o livro dos Nomes de Deus, uma Vindicación de la cabala, um Examen de la filosofía de Robert Flood, uma tradução literal do Sepher Yezirah, uma Biografía del Baal Shem, uma Historia de la secta de los Hasidim, uma monografia sobre a nomenclatura divina do Pentateuco. Como uma característica da obra de Borges, o conto faz referências a autores e títulos pouco acessíveis ao leitor comum. Poder-se-ia acusar o autor de excesso de cultismo, se essas referências fossem meras citações. A alusão a essas obras esotéricas, entretanto, justifica-se plenamente, uma vez que constitui parte do argumento do conto e a suposta causa dos assassinatos, bem como a ordem em que eles ocorrem, ligam-se diretamente aos princípios esotéricos emanados dos textos.

Um segundo crime é cometido em um subúrbio a Oeste da cidade, na noite de 3 de janeiro e forma a segunda letra do nome, conforme algumas palavras garatujadas junto ao cadáver: "La segunda letra del Nombre ha sido articulada" (BORGES, 1996, p. 501, v.I).

No Leste da cidade, no dia 3 de fevereiro, ocorre um suposto terceiro assassinato, mas não se descobre cadáver algum. Somente uma mancha de sangue e a previsível frase rabiscada: "La última de las letras del Nombre ha sido articulada." (BORGES, 1996, p. 502 v. I), o que vai se configurando, para Lönnrot, serem esses assassinatos sacrifícios místicos de uma seita judaica, os Hasidim.

A primeiro de março a polícia recebe uma carta avisando que no próximo dia 3 não haveria um quarto crime porque a 
O nome sugere o filósofo Baruch Spinoza (1632-1677), de origem judaico-holandesa.

8 De acordo com os estudiosos, a Cabala busca uma aproximação do homem a Deus, por intermédio do seu Nome que, na mitologia judaica, pode ser designado pela palavra grega tetragrammaton. Do grego tetra, quatro e gramma, letra, o tetragrama é representado pelas letras $\mathrm{YHVH}$ (às quais a tradição acrescentou os sinais vocálicos e chamou de 'Jeová' ou 'Senhor' em algumas traduções da Bíblia em Português (NASCIMENTO, Lyslei de Souza. Vestígios da tradição judaica: Borges e outros rabinos. 2001. Tese - Curso de Pós Graduação em Letras, Universidade Federal de Minas Gerais, Belo Horizonte).

9 Expressão latina, significando "de acordo com os métodos da geometria", em uma referência explícita à obra de Spinoza More geométrico demonstrata (FISHBURN; HUGHES 1990, p. 233). localização dos três crimes anteriores, respectivamente no Norte, Oeste e Leste da cidade, formam "los vértices perfectos de un triángulo equilátero y místico". Junto ao comunicado há um mapa da cidade, no qual está desenhado, em tinta vermelha, um triângulo com os três pontos cardeais. A carta é assinada por um tal "Baruch Spinoza", ${ }^{7}$ nome que incita e desafia a racionalidade de Lönnrot.

Por outro lado, de acordo com o material recebido, o espaço demarcado por um triângulo e as datas dos crimes (3 de dezembro, 3 de janeiro e 3 de fevereiro) obedeceria a uma ordem que tem por base o número três. Assim, a possibilidade de novos assassinatos estaria descartada para a polícia, mas não para Lönnrot, detetive racional, sagaz e desconfiado. Com a ajuda de uma bússola, de um compasso e da palavra "Tetragrámaton", ele chega à dedução lógica de que a primazia do número três é enganadora. Contra todas as aparências, haverá um quarto crime. Lönnrot baseia-se em algumas evidências (entre elas, o fato de as letras no Tetragrámaton serem quatro e não três) e conclui que a série de crimes não é tríplice, mas quádrupla. Conseqüentemente, a figura geométrica que indica no mapa a localização dos crimes não deve ser um triângulo, mas um losango. Assim, por meio de um procedimento more geometrico, ${ }^{9}$ e utilizando uma bússola e um compasso, o detetive prevê exatamente o local ao Sul da cidade onde ocorrerá o quarto crime e que define "el punto que determina un rombo perfecto" (BORGES, 1996, p. 507, v. I): a quinta abandonada de Triste-le-Roy. Para lá ele se dirige.

Ao percorrer a casa, Lönnrot constata que ela possui muitas "inútiles simetrías": escadas, terraços, salas, esculturas, espelhos. Dessa forma, a casa é a representação de um labirinto em que tudo é duplo, como a imagem dos espelhos. Lá o inspetor é feito prisioneiro de Red Scharlach, velho inimigo, e só então compreende que ele próprio é a quarta vítima. Antes de matar o inspetor, e para completar seu triunfo, Scharlach revela a razão dos crimes e o labirinto criado para capturar Lönnrot. O último deles, agora iminente, tem como vítima o próprio detetive. Compreendendo, por fim, que foi ludibriado e vai morrer, Lönnrot ainda quer ter a última palavra:

- En su laberinto sobran tres líneas - dijo por fin -. Yo sé de un laberinto griego que es una línea única, recta. En esa línea se han perdido tantos filósofos que bien puede perderse un mero detective. Scharlach, cuando en otro avatar usted me dé caza, finja (o cometa) un crimen en A, luego un segundo crimen en $\mathrm{B}$, a 8 kilómetros de $\mathrm{A}$, luego un tercer crimen en $\mathrm{C}$, a 4 kilómetros de $\mathrm{A}$ y de $\mathrm{B}$, a mitad de camino entre los dos. Aguárdeme después en $\mathrm{D}$, a 2 kilómetros de $\mathrm{A}$ y de $\mathrm{C}$, de nuevo a mitad de camino. Máteme en $\mathrm{D}$, como ahora va a matarme en Triste-le-Roy. (BORGES, 1996, p. 507, v. 1) 
10 Famosos são os paradoxos de Zenão de Eléia, cujo objetivo era a refutação, por redução ao absurdo, do pluralismo e do mobilismo, procurando mostrar os paradoxos envolvidos na idéia de movimento. $\mathrm{O}$ mais famoso desses paradoxos é o de Aquiles e a tartaruga. (Paradoxo. In: JAPIASSU, Hilton; MARCONDES, Danilo. Dicionário básico de Filosofia. Rio de Janeiro: Zahar, 1993, p.189). Segundo o primeiro deles, Aquiles, o homem mais veloz da Ática, corre contra a tartaruga, o animal mais lento da criação. Arbitrariamente, Zeno estabelece que Aquiles é dez vezes mais rápido que a tartaruga e lhe dá cem metros de vantagem na corrida. De acordo com essa proposição, quando Aquiles corre os cem metros, a tartaruga avança a décima parte. Quando Aquiles avança os dez metros, a tartaruga avança um metro. Aquiles se adianta um metro e a tartaruga, um centímetro... e, assim, interminavelmente. Na realidade, Aquiles supera de imediato a tartaruga. Porém, para a razão, essa vitória é impossível e a corrida é infinita. Aquiles pode correr para sempre e nunca alcançar a tartaruga.

11 A imunidade do detetive, como regra do gênero policial clássico, ou de enigma, é enfatizada por Todorov, ao descrever as "espécies" de narrativa policial (TODOROV, 1969, p. 99).
Descobrindo que Scharlach baseou seu labirinto em um triângulo e em um quadrilátero, o inspetor lhe propõe outro novo labirinto de uma linha só: o paradoxo de Zeno. ${ }^{10}$ Citar Zeno é a solução do detetive, para vencer seu inimigo. Ao apresentar esse outro labirinto - que Scharlach aceita - Lönnrot não está apenas propondo mais um jogo intelectual: está também reescrevendo seu destino. É de se supor que Lönnrot, conhecedor das teorias de Zeno, pense que, na subdivisão infinita do espaço, Scharlach nunca poderá alcançá-lo.

Segundo Barili, com "La muerte y la brújula" Borges, leitor de policiais, se estabelece na tradição do gênero, desenvolvido principalmente por britânicos e norte-americanos, e, justamente por não ser produto direto dessa cultura, move-se com grande liberdade para inovar, maneja com perícia o legado recebido e altera suas convenções, em uma clara afirmação de sua identidade como escritor latino-americano (BARILI, 1999, p. 188). Pode-se mesmo afirmar que Borges subverte o gênero e dilui suas fronteiras, recriando-o. Uma de suas muitas inovações refere-se às personagens canônicas do gênero: detetive, criminoso, vítima. Na narrativa policial clássica é o detetive quem, no final, esclarece o mistério, depois de desprezar as prosaicas e geralmente falsas soluções do comissário de polícia. Em "La muerte y la brújula", em uma crucial transgressão, o detetive é assassinado quando lhe é revelado o motivo "de la periódica serie de hechos de sangre" (BORGES, 1996, p. 499 v. I), que não consegue impedir. Assim, inverte-se o binômio criminoso/detetive de forma que o detetive, perseguidor, se transforma na vítima, perseguida. E, inversamente, o perseguido se converte no detetive perseguidor. É o criminoso quem, conhecedor do modo de atuar do detetive, se antecipa aos seus raciocínios e o captura em uma armadilha fatal. ${ }^{11}$ Ao final, é ele quem fornece a verdadeira explicação dos fatos, baseado no que acredita ser verdadeiro.

Parece que Borges, escritor, utiliza as palavras de Scharlach para falar diretamente a seu leitor, explicando-lhe os artifícios de sua escritura, desfamiliarizando-o de uma leitura convencional e propondo-lhe infinitas possibilidades de leitura (BARILI, 1999, p. 200).

Assim, ao mostrar ironicamente as convenções e limitações do gênero, Borges, além de subvertê-lo e recriá-lo, obriga o leitor a refletir sobre o que está lendo, tornando-se um colaborador, um escritor do texto, a partir de suas experiências e leituras.

A narrativa ambienta-se numa metrópole à qual Borges prefere não dar nome, nem situar geograficamente. No prólogo a Artificios o escritor esclarece:

pese a los nombres alemanes o escandinavos, ocurre en un Buenos Aires de sueños: la torcida Rue de Toulon es el Paseo de Julio; Triste-le-Roy, el hotel donde Herbert 
12 Note-se que o conto não propõe apenas um retrato de Buenos Aires, ainda que alterando-lhe as feições, mas o cenário poderia ser estendido pelo mundo afora, cita Borges no prólogo de Artificios: "Ya redactada esa ficción, he pensado en la conveniencia de amplificar el tiempo y el espacio que abarca: la venganza podría ser heredada; los plazos podrían computarse por años, tal vez por siglos; la primera letra del Nombre podría articularse en Islandia; la segunda, en Méjico; la tercera, en el Indostaní" (BORGES, 1996, p. 483 v.I). Nesse sentido, a cidade tornar-se-ia, também, uma réplica do mundo, em outras dimensões.

13 Ao comentar o estilo literário de Borges, ALAZRAKI (1983: 199) enfatiza que ele consegue extrair das coisas comuns sua poesia intrínseca, sem prejuízo da prosa, pois "no se trata de la poesía de las palavras sino de las cosas". Aponta os traços líricos, que, elucida, tratam-se de "verdaderos puentes poéticos", nunca de desvios, e são parte integrante da trajetória da narrativa; ocorrem, sobretudo, quando Borges enfoca alguns temas, como a tarde, a planície e a cidade de Buenos Aires.
Ashe recibió, y tal vez no leyó, el tomo undécimo de una enciclopedia ilusoria. (BORGES, 1996, p. 483, v. I) ${ }^{12}$

Também em um diálogo mantido com Alifano, Borges esclarece que coloca, neste conto, muitas das suas recordações de Buenos Aires e seus subúrbios.

La Quinta Triste-le-Roy es una versión exaltada y distorsionada del espacioso hotel Las Delicias, de Adrogué, donde yo viví parte de mi juventud. [...] El Hôtel du Nord es el Plaza Hotel. En cuanto al estuario no es otro que el Río de la Plata. (BORGES in ALIFANO, 1988, p. 106)

Borges consegue transmitir como que um sentimento de nostalgia pela Buenos Aires de sua juventude, o que, na opinião de alguns críticos, é um dos maiores méritos de "La muerte y la brújula". Alifano (1988, p. 106), por exemplo, afirma que "ese cuento [...] se sostiene más por su atmósfera que por su trama, aunque su trama es perfecta, inobjetable". Assim, Borges transforma suas próprias vivências em material literário que expressa seu sentir argentino e apesar de não enfocar temas tipicamente argentinos, o conto encerra, como mostra o fragmento abaixo, um sabor de sua cidade natal:

A izquierda y a derecha del automóvil, la ciudad se desintegraba; crecía el firmamento y ya importaban poco las casas y mucho un horno de ladrillos o un álamo. Llegaron a su pobre destino: un callejón final de tapias rosadas que parecían reflejar de algún modo la desaforada puesta de sol. (BORGES, 1996 , p. 501, v. I). ${ }^{13}$

Pode-se dizer que essa Buenos Aires "de sueños" não é simplesmente um cenário, em que as personagens vagueiam com desenvoltura, mas uma circunstância, mesmo, dessas personagens. Mais do que o locus, a cidade é também personagem da história.

É importante ressaltar que a teoria de que Lönnrot e Scharlach são a mesma pessoa apóia-se na noção panteísta de que um homem é os outros, ou na idéia de que todos os homens são de alguma maneira a mesma pessoa (o que significa a anulação da identidade individual), constante preocupação filosófica de Borges, presente em outros contos, como em "El acercamiento a Almotásim", já analisado. Outras narrativas de Borges abordam o tema, como "La forma de la espada":

Me abochornaba ese hombre con miedo, como si yo fuera el cobarde, no Vincent Moon. Lo que hace un hombre es como si lo hicieran todos los hombres. Por eso no es injusto que una desobediencia en un jardín contamine al género humano; por eso no es injusto que la crucifixión de un solo judío baste para salvarlo. Acaso Schopenhauer tiene razón; yo soy los otros, cualquier hombre es todos los hombres, Shakespeare es de algún modo el miserable John Vincent Moon. (BORGES, 1996 p. 493 , v.I) 
O mesmo conceito é utilizado em "Tlön, Uqbar, Orbis Tertius": "Todos los hombres, en el vertiginoso instante del coito, son el mismo hombre. Todos los hombres que repiten una línea de Shakespeare, son William Shakespeare" (BORGES, 1996, p. 438, v.I).

Também é recorrente nos contos de Borges a tese de que se alguém participa de uma entidade qualquer, ele é essa entidade; ou que uma circunstância similar, unindo várias pessoas, faz dessas pessoas uma só. No poema "El truco", de Fervor de Buenos Aires, o conceito é enriquecido, ao aparecer perpetuado no fato de que todos que realizam uma mesma ação básica e ritual perdem a identidade individual e se tornam, de certa forma, imortais. A idéia é a de que os jogadores do passado, mortos, voltam a viver nos jogadores que, hoje, reproduzem as mesmas apostas; assim, a repetição de um ato ritualizado suspende e apaga o tempo histórico e confere eternidade aos que o praticam. ${ }^{14}$

Assim, neste artigo, procurei mostrar a opção por um gênero literário tradicionalmente considerado "marginal" feita por um dos escritores mais representativos da literatura hispanoamericana. Ao analisar dois contos policiais de Jorge Luis Borges, espero ter conseguido demonstrar que o policial em Borges aparece vinculado a preocupações que ultrapassam o gênero, abrangendo desde questões literárias a metafísicas. Também é possível confirmar nos seus contos policiais a presença de temas que são comuns às suas narrativas, policiais ou não. Dessa forma, verifica-se que a ficção policial que compõe a obra do escritor argentino vai muito além do gênero que ele conseguiu, como foi visto, subverter e até recriar, e merece ser lida como a expressão de um pensamento literário universal. Na verdade, a contribuição de Jorge Luis Borges ${ }^{15}$ à ficção policial vai mais além: ao se dedicar a um gênero considerado "menor" (hoje menos do que ontem), que despertava pouca atenção da crítica do ponto de vista da estrita literariedade, o escritor como que concorre para sua legitimação, oportunizando estudos mais abrangentes do texto policial, sob uma perspectiva menos preconceituosa.

\footnotetext{
14 Ver MONEGAL (1987, p. 102) e SABATO (1976, p. 72).

15 E outros escritores que, segundo Vera Lúcia Follain de Figueirado, historicamente não se identificam com o universo da cultura de massa, como Mario Vargas Llosa, Gabriel Garcia Márquez, Rubem Fonseca (FIGUEIREDO, 1998, p. 20).
} 


\begin{abstract}
The work of Jorge Luis Borges had a decisive influence on the profile of the $20^{\text {th }}$ century, especially concerning the literary world. An acclaimed writer, he revealed an undeniable preference for marginal literature, for text outside the canonic traditions. The present work focuses on two tales by Borges that belong to a genre still considered "minor," the detective story. Also, it shows how these narratives appear tied to concerns that go beyond the genre, encompassing some usual elements of the Borgian universe such as philosophy, theology, mysticism, myth, metaphysics, and history.
\end{abstract}

Keywords: Borges; Canon; Transgression; Detective story.

\title{
Referências
}

ALAZRAKI, Jaime. La prosa narrativa de Jorge Luis Borges. Madrid: Gredos, 1983.

ALIFANO, Roberto. Conversaciones con Borges. Buenos Aires: Torres Agüero, 1994.

ÂNGELO, Andréa Lúcia Padrão. Tradição e transgressão no conto policial de Jorge Luis Borges. 2006. 213f. Tese (Doutorado em Literatura)-Centro de Comunicação e Expressão, Universidade Federal de Santa Catarina, Florianópolis, 2006.

BALDERSTON, Daniel. El precursor velado: R.L. Stevenson en la obra de Borges. Tradução de Eduardo Paz Leston. Buenos Aires: Sudamericana, 1985. Disponível em: <http://www.hum.au.dk/ romansk/borges/bsol/db5.htm>. Acesso em: 5 mar. 2005.

. Tradição e traição: Borges e Stevenson. Folha de São Paulo, São Paulo, 19 ago. 1984. Caderno Folhetim, p. 11.

BARILI, Amelia. Jorge Luis Borges y Alfonso Reyes: la cuestión de identidad del escritor latinoamericano. México: Fondo de Cultura Económica, 1999.

BORGES, Jorge Luis. Borges en Sur. 1931-1980. Buenos Aires: Emecé, 1999a.

. El acercamiento a Almotásim. In: . Obras completas. v. 1: historia de la eternidad. Barcelona: Emecé, 1996a.

El cuento policial. In: Borges oral. Buenos Aires: Emecê: Editorial de Belgrano, 1997.

El jardín de senderos que se bifurcan. In: . Obras completas. v. 1: ficciones. Barcelona: Emecé, 1996b. 
. Excellent intentions, de Richard Hull. In: . Obras

completas. v. 4: textos cautivos. Barcelona: Emecé, 1996c. 1996d. . Ficciones. In: . Obras completas . Barcelona: Emecé, La muerte y la brújula. In: ficciones. Barcelona: Emecé, 1996e. La forma de la espada. In: artificios. Barcelona: Emecé, 1996f. . Obras completas. v. 1: Los laberintos policiales y Chesterton. In: Borges en sur 1931-1980. Buenos Aires: Emecé, 1999b.

Modos de G.K. Chesterton. In: Borges en sur. Buenos Aires: Emecé, 1999c.

Tema del traidor y del héroe. In: . Obras completas. v. 1: ficciones. Barcelona: Emecé, 1996g. The paradoxes of Mr. Pond, de G.K.Chesterton. In: 1996h.

Obras completas. v. 4: textos cautivos. Barcelona: Emecé,

Tlön, Uqbar, Orbis Tertius. In: v. 1: ficciones. Barcelona: Emecé, $1996 \mathrm{i}$. . Obras completas.

; CASARES, Adolfo Bioy. Que es el cuento policial? In: LAFFORGUE, Jorge; RIVERA, Jorge. Asesinos de papel: ensayos sobre narrativa policial. Buenos Aires: Colihue, 1995. 1977. . Los mejores cuentos policiales. 4. ed. Buenos Aires: Emecé,

BORGES, Jorge Luis; FERRARI, Osvaldo. Edgar Allan Poe. In: . Diálogo II. Buenos Aires: Sudamericana, 1998. . El cuento policial. In: Diálogo I. Buenos Aires: Editorial Sudamericana, 1998.

BORGES, Jorge Luis; SÁBATO, Ernesto; BARONE, Orlando. Diálogos: Borges e Sábato. 2. ed. Buenos Aires: Emecé, 1996.

FIGUEIREDO, Vera Lúcia Follain de. O assassino é o leitor. Matraga, Rio de Janeiro, v. 3, n. 4-5, p.20, jan./ago. 1988.

FISHBURN, E.; HUGHES, P. Un diccionario de Borges. Buenos Aires: Torres Agüero, 1995.

JAPIASSU, Hilton; MARCONDES, Danilo. Dicionário básico de Filosofia. Rio de Janeiro: J. Zahar, 1993.

MONEGAL, Emir R. Uma poética de leitura. Trad. Irlemar Chiampi. São Paulo: Perspectiva, 1987.

NASCIMENTO, Lyslei de Souza. Vestígios da tradição judaica: Borges e outros rabinos. 2001. Tese (Doutorado em Letras)Universidade Federal de Minas Gerais, Belo Horizonte, 2001. 
RIVERA, Jorge B. Borges y lo policial. In: LAFFORGUE, Jorge; RIVERA, Jorge. Asesinos de papel: ensayos sobre narrativa policial. Buenos Aires: Colihue, 1995.

SÁBATO, Ernesto. Los relatos de Jorge Luis Borges. In: ALAZRAKI, Jaime (Ed.). Jorge Luis Borges. Madrid: Taurus, 1976.

SARLO, Beatriz. Borges, un escritor en las orillas. Buenos Aires: Seix Barral, 2003.

. La pasión y la excepción: Eva, Borges y el asesinato de Aramburu. Buenos Aires: Siglo XXI, 2004.

STRATTA, Isabel. Borges, un heredero parcial. Fragmentos, Florianópolis, n.17, p. 55-62, jul./dez. 1999.

TODOROV, Tzvetan. As estruturas narrativas. São Paulo: Perspectiva, 1969.

VÁZQUEZ, María Esther. Borges: imagines, memorias, diálogos. Caracas: Monte Ávila, 1977. 